\title{
PCA3 long noncoding RNA modulates the expression of key cancer-related genes in LNCaP prostate cancer cells
}

\author{
Ana Emília Goulart Lemos ${ }^{1}$ - Luciana Bueno Ferreira ${ }^{2}$ - Nadia Maria Batoreu ${ }^{1}$. \\ Paula Priscilla de Freitas ${ }^{3,4}$ - Martin Hernan Bonamino ${ }^{4,5}$. \\ Etel Rodrigues Pereira Gimba ${ }^{4,6}$
}

\begin{abstract}
Prostate cancer antigen 3 (PCA3) is a prostate-specific long noncoding RNA (lncRNA) involved in the control of prostate cancer (PCa) cell survival, through modulating androgen receptor(AR) signaling. To further comprehend the mechanisms by which PCA3 modulates LNCaP cell survival, we characterized the expression patterns of several cancer-related genes, including those involved in epithelial-mesenchymal transition (EMT) and AR cofactors in response to PCA3 silencing. We also aimed to develop a strategy to stably silence PCA3. Small interfering RNA (siRNA) or short hairpin RNA (shRNA) was used to knock down PCA3 in LNCaP cells. The expression of 84 cancer-related genes, as well as those coding for AR cofactors and EMT markers, was analyzed by quantitative real-time PCR (qRT-PCR). LNCaPPCA3 silenced cells differentially expressed 16 of the 84 cancer genes tested, mainly those involved in gene expression control
\end{abstract}

Electronic supplementary material The online version of this article (doi:10.1007/s13277-016-5012-3) contains supplementary material, which is available to authorized users.

Etel Rodrigues Pereira Gimba etelgimba@id.uff.br

Fundação Oswaldo Cruz, Bio-Manguinhos, Rio de Janeiro, Brazil

2 Instituto de Patologia Molecular e Imunologia da Universidade do Porto, Porto, Portugal

3 Fundação Centro Universitário Estadual da Zona Oeste, Rio de Janeiro, Brazil

4 Instituto Nacional de Câncer José Alencar Gomes da Silva, Coordenação de Pesquisa, Rio de Janeiro, Brazil

5 Fundação Oswaldo Cruz, Vice-presidência de Pesquisa e Laboratórios de Referência, Rio de Janeiro, Brazil

6 Universidade Federal Fluminense, Instituto de Humanidades e Sáude, Departamento de Ciências da Natureza, Rio de Janeiro, Brazil and cell signaling. PCA3 knockdown also induced the upregulation of several transcripts coding for AR cofactors and modulated the expression of EMT markers. LNCaP cells transduced with lentivirus vectors carrying an shRNA sequence targeting PCA3 stably downregulated PCA3 expression, causing a significant drop $(60 \%)$ in the proportion of $\mathrm{LNCaP}$ cells expressing the transgene. In conclusion, our data provide evidence that PCA3 silencing modulates the expression of key cancer-related genes, including those coding for AR cofactors and EMT markers. Transducing LNCaP cells with an shRNA sequence targeting PCA3 led to loss of viability of the cells, supporting the proposal of PCA3 knockdown as a putative therapeutic approach to inhibit PCa growth.

Keywords PCA3 · Long noncoding RNA · Gene expression · Cancer-related genes · Prostate cancer

\section{Introduction}

Prostate cancer antigen 3 (PCA3) is a prostate-specific long noncoding RNA (lncRNA) that is highly expressed in prostate cancer (PCa) tissues compared to normal prostate specimens [1-3]. The gene encoding PCA3 is located on chromosome $9 q 21-22$ in antisense orientation within intron 6 of BMCC1 (prune homolog 2 (PRUNE2) gene) [3].

Although PCA3 expression is observed in PCa cells, it seems to be restricted to cell lines that are androgen-dependent, such as LNCaP cells [4]. Based on this evidence for a link between PCA3 and androgen receptor (AR) signaling, our group previously demonstrated that PCA3 modulates PCa cell survival in part through the AR pathway [5]. Besides classically controlling prostate development, tumorigenesis, and apoptosis inhibition, AR signaling represents a key target for PCa treatment approaches. Hence, androgen 
blockade and/or androgen signaling axis impairment represents key targets for PCa treatment strategies [6]. Androgens induce AR conformational changes, phosphorylation, dimerization, and then nuclear translocation. Once in the nucleus, $\mathrm{AR}$ can bind to androgen-response elements (AREs) in the promoter regions of AR target genes. Moreover, AR cofactors or coregulators, including coactivators and corepressors, also bind the AR complex, facilitating or preventing, respectively, their interaction with the general transcription apparatus. Activation or repression of AR target genes leads to biological responses such as cell growth and survival [7].

Recent reports have indicated that AR signaling and the epithelial-mesenchymal transition (EMT) program can cross talk, stimulating cancer progression [8, 9]. During the EMT program, epithelial cells downregulate the expression of cell adhesion molecules, such as E-cadherin, while they upregulate mesenchymal markers (such as $\mathrm{N}$-cadherins and vimentin). Besides mediating EMT-related embryonic development, this program has been extensively correlated with tumor cell survival and chemotherapeutic resistance [10, 11]. Functional changes in the components of the AR axis, especially the AR, can induce the EMT process during tumor progression [8]. Moreover, androgens mediate $\beta$-catenin activation, which could be an alternative route by which the AR pathway induces EMT in PCa epithelial cells [8].

Many studies have also shown that androgen-AR signaling affects key events during prostate carcinogenesis. As a result of AR signaling activation, the expression of several cancerrelated genes is modulated, promoting different aspects of prostate carcinogenesis, including cell proliferation, apoptosis, and PCa metastasis [6].

Noncoding RNAs have been broadly described as key regulators of cancer-related genes and their corresponding signaling pathways $[12,13]$. In the present report, we further characterize gene expression patterns that may be related to PCA3 roles in modulating $\mathrm{PCa}$ cell survival and AR signaling in LNCaP cells. We investigated how PCA3 downregulation can modulate transcription levels of key cancer-related genes, AR cofactors, and EMT markers. The LNCaP PCa cell line was chosen as a model to study PCA3-related transcription events, since PCA3 is expressed at higher levels in this androgen-responsive cell [4]. We also developed a strategy to stably silence PCA3, as a possible tool for future therapeutic strategies aiming to decrease the survival of androgendependent PCa cancer cells.

\section{Material and methods}

\section{Cell culture}

The LNCaP PCa cell line was provided by the ATCC (Rockville, MD, USA) and maintained in RPMI-1640 medium (Sigma) supplemented with $10 \%$ heatinactivated fetal bovine serum (FBS) (Invitrogen/Life Technologies, Inc.), L-glutamine (2 mM), $100 \mathrm{U} / \mathrm{mL}$ penicillin, and $100 \mu \mathrm{g} / \mathrm{mL}$ streptomycin. The LNCaP cell line was chosen for this study based on our previous data showing that it expresses higher PCA3 levels than DU145, PC3, and even the RWPE-1 nontumoral cell line [5]; 293T cell line was maintained in Dulbecco's modified Eagle's medium (DMEM) (Invitrogen) with $10 \%$ FBS, Lglutamine $(2 \mathrm{mM}), 100 \mathrm{U} / \mathrm{mL}$ penicillin, and $100 \mu \mathrm{g} / \mathrm{mL}$ streptomycin.

\section{PCA3 expression knockdown by siRNA}

Small interfering RNAs targeting PCA3 exon 4 (siPCA3-5' CUAGCACACAGCAUGAUCAUUACGG 3') and a scramble small interfering RNA (siRNA) sequence (siScrbl-5' GCACGCUCCUACGAAUGCUAGUAAA 3') were designed and synthesized by IDT Technologies. The siPCA3 sequence efficiently downregulates PCA3 expression, as previously demonstrated by our group [5]. Both siRNAs were affinity-purified and annealed before use. One day before transfection, LNCaP cells were plated into $2.0 \mathrm{~mL}$ of RPMI without antibiotics and supplemented with $0.5 \%$ FBS at a density of $2.5 \times 10^{5}$ cells, in six-well culture dishes. After $24 \mathrm{~h}$, the RPMI medium in each well was replaced with $1.5 \mathrm{~mL}$ of fresh medium. Transfections were performed using $60 \mathrm{nM}$ of each siPCA3 or siScrbl, using Lipofectamine 2000 (Invitrogen), as described by the manufacturer. Cells were then kept in culture for $36 \mathrm{~h}$, and PCA3 transcript expression was evaluated by quantitative real-time PCR (qRT-PCR) analysis, using the following oligonucleotide sequence pairs: PCA3 F (5' TTCAAAGACCCTTCGTGTTGCTGC $3^{\prime}$ ) and PCA3 R (5' ATCTTGAGATGCTTCCCAGCCTGT 3'). As a constitutive gene, $18 \mathrm{~S}$ expression was used in these assays, with the oligonucleotide sequence pairs: $18 \mathrm{~S} F\left(5^{\prime}\right.$ AACCCGTTGAACCCCATT 3') and $18 \mathrm{~S} \mathrm{R} \mathrm{(5'}$ CCATCCAATCGGTAGTAGCG $3^{\prime}$ ). Conditions for PCR amplification of PCA3 transcripts were as follows: $50{ }^{\circ} \mathrm{C}$ ( $2 \mathrm{~min}), 94^{\circ} \mathrm{C}(5 \mathrm{~min})$ followed by 40 cycles at $94{ }^{\circ} \mathrm{C}(30 \mathrm{~s})$, $60{ }^{\circ} \mathrm{C}(30 \mathrm{~s})$, and $72{ }^{\circ} \mathrm{C}(45 \mathrm{~s})$. To evaluate the specificity of PCR products, a melting curve analysis was performed after each reaction.

\section{Total RNA isolation and reverse transcription}

Total RNA from LNCaP cells was purified with the RNeasy Mini Kit (Qiagen) and treated with RNase-free DNase (Qiagen) during the RNA purification process. One microgram of RNA was reverse-transcribed using a "Superscript II First-Strand Synthesis System for RT-PCR" complementary DNA (cDNA) Synthesis kit (Invitrogen). 


\section{Quantitative real-time PCR}

Quantitative real-time PCR (qRT-PCR) was performed using a CFX96 Real-Time System (Bio-Rad) C1000 Thermal Cycler, cDNA from LNCaP cells, and SYBR Green (Applied Biosystems) as the fluorophore, following the manufacturer's instructions. Oligonucleotide primers used for qRT-PCR expression analysis of EMT markers and AR cofactors are listed in Online Resource 1. The expression analysis of these gene products was normalized based on the reference gene $\beta$-actin, using the $\Delta \Delta \mathrm{CT}$ method. Conditions for PCR amplification of EMT markers were as follows: $50^{\circ} \mathrm{C}(2 \mathrm{~min})$, $94{ }^{\circ} \mathrm{C}(5 \mathrm{~min})$ followed by 40 cycles at $94{ }^{\circ} \mathrm{C}(30 \mathrm{~s}), 60^{\circ} \mathrm{C}$ (30 s), and $72{ }^{\circ} \mathrm{C}(45 \mathrm{~s})$. Conditions for PCR amplification of AR-cofactors were as follows: $50{ }^{\circ} \mathrm{C}(2 \mathrm{~min}), 95^{\circ} \mathrm{C}(10 \mathrm{~min})$, followed by 40 cycles at $95^{\circ} \mathrm{C}(30 \mathrm{~s}), 60^{\circ} \mathrm{C}(60 \mathrm{~s})$, and $72{ }^{\circ} \mathrm{C}$ (40 s). To evaluate the specificity of the PCR products, a melting curve analysis was performed after each reaction.

\section{PCR array}

The Human Cancer Pathway Finder SuperArray (PAHS033A; Qiagen) was used to determine changes in the transcription expression levels of several key cancer-related genes, representing the main hallmarks of cancer in response to PCA3 silencing in LNCaP cells. This array was chosen because it contains genes that code for several pathways related to cancer progression and tumor cell survival.

We analyzed the RNA expression levels of 84 genes related to DNA damage repair, apoptosis and cell senescence, signal transduction molecules and transcription factors, adhesion, angiogenesis, invasion, and metastasis. The assay used five housekeeping genes ( $\beta 2$ microglobulin, hypoxanthine, phosphoribosyltransferase 1, ribosomal protein L13a, GAPDH, and $\beta$-actin) to normalize gene expression levels. In addition, the array contained positive, reverse transcription and genomic DNA contamination controls. Two independent experiments with technical triplicates of the siPCA3 and siScrbl transfection assay were performed in order to compare total cDNA from LNCaP siPCA3-transfected cells with that from siScrbl-transfected cells. The PCR array plates were run using the CFX96 Real-Time System cycler (Bio-Rad, Hercules, CA), following a SuperArray two-step cycling protocol, in which each plate was run for 1 cycle for $10 \mathrm{~min}$ at $95^{\circ} \mathrm{C}$, followed by 40 cycles of $95^{\circ} \mathrm{C}$ for $15 \mathrm{~s}$ and $60{ }^{\circ} \mathrm{C}$ for $1 \mathrm{~min}$. After the Super Array protocol was run, qRT-PCR data were analyzed using the software provided on the website, in order to compare gene expression of LNCaP-siPCA3transfected cells with that of LNCaP cells transfected with the siScrbl sequence. Total RNA quality control, cDNA synthesis, and the qRT-PCR array were performed as recommended by the manufacturers. Gene expression data were analyzed using a standard Excel-based PCR Array Data
Analysis software provided by Qiagen. Fold changes in gene expression were calculated using the $\Delta \Delta \mathrm{CT}$ method. Only genes showing a twofold or greater change in gene expression levels, using $p<0.05$, were considered statistically significant and were used for further analysis.

\section{Generation of LNCaP cells stably silencing PCA3}

PCA3-specific and scramble short hairpin RNAs (shRNAs) were designed based on siPCA3 and siScrbl sequences as shown in Online Resource 2. shRNA oligonucleotides were synthesized (Invitrogen, São Paulo, Brazil), annealed, phosphorylated, and then cloned into ClaI and MluI restriction sites of alkaline phosphatase-treated pLVTHM vector (http://www. addgene.org/lentiviral/pLVTHM-guide/). Cloned shRNA sequences were confirmed by DNA sequencing. Recombinant plasmids were transfected by calcium phosphate precipitation into $293 \mathrm{~T}$ packaging cells, using a second-generation packing system and VSV tropism, as previously described [14]. LNCaP cells were transduced by 48-h exposure to viral vectors. After transduction, the cells obtained were termed LNCaP empty pLVTHM, LNCaP shPCA3, and LNCaP shScrbl PCA3.

LNCaP cells transduced with the lentiviral vector containing the shPCA3 or the scrambled shRNA were analyzed in an Axio Observer Z1 inverted fluorescence microscope (Zeiss, Germany). Images were acquired with AxioVision Rel 4.8 software. Total cell numbers were counted and green fluorescent protein (GFP)-positive (GFP+) cell numbers determined in five different gates, using the Adobe Photoshop CS6 program. For the long-term follow-up experiment, the percentage of LNCaP GFP+ cells was evaluated up to $72 \mathrm{~h}$ after cell transduction by microscopy and thereafter by flow cytometry analysis (FACSCalibur ${ }^{\mathrm{TM}}$ device). Flow cytometry data were analyzed using the software CellQuest (BD Biosciences) and FlowJo.

\section{Cell viability assays}

LNCaP cells were sedimented by centrifugation and resuspended in $300 \mu \mathrm{L}$ of phosphate-buffered saline (PBS) for cell viability analysis. Trypan blue $(0.4 \%$ in PBS; $10 \mu \mathrm{L})$ was added to a $10 \mu \mathrm{L}$ aliquot of cell suspension, and the number of unstained viable cells was counted.

\section{Statistical analysis}

The analyses of the EMT-related genes and AR-cofactor expression are shown as the mean \pm standard deviation of two biological replicates, each with three technical replicates. The Wilcoxon signed-rank test was used for statistical analysis of these data. $p$ values $\leq 0.05$ were taken to indicate significantly different expression of genes. 


\section{Results}

PCA3 can modulate the expression of several genes related to cancer hallmarks

As an approach to ascertain the cancer-related pathways that could control the roles of PCA3 in modulating LNCaP cell survival, AR signaling, and related phenotypes, we assessed how PCA3 downregulation (which was validated for these assays using qRT-PCR; Online Resource 3) could modulate the expression of genes involved in different hallmarks of cancer by a qRT-PCR array analysis, using the Cancer Pathway Finder Array (Qiagen). This array consists of 84 genes representing the major biological pathways involved in key cancer signaling pathways, as described in the "Material and methods" section. We then compared the expression levels of these genes using total RNA extracted from LNCaP siPCA3-transfected cells and LNCaP siScrbltransfected cells, which were used as controls. Among the 84 cancer pathway-focused genes tested, 16 genes were differentially expressed in LNCaP siPCA3-transfected cells compared to controls ( $p<0.05$ with at least 2.0 -fold upregulation or downregulation). Most of these genes code for signal transduction molecules (MAP2K1, ERBB2, PIK3R1) and transcription factors (FOS and JUN) (Fig. 1). The remaining gene products are related to angiogenesis (IFNB1, COL18A1, and VEGFA), apoptosis and cell senescence (TERT, BAD, and TNFRSF25), invasion and metastasis (MTA2 and PLAUR), cell adhesion (MTSS1 and ITGB1), and DNA damage repair (BRCA1) (Fig. 1). A complete list of genes with

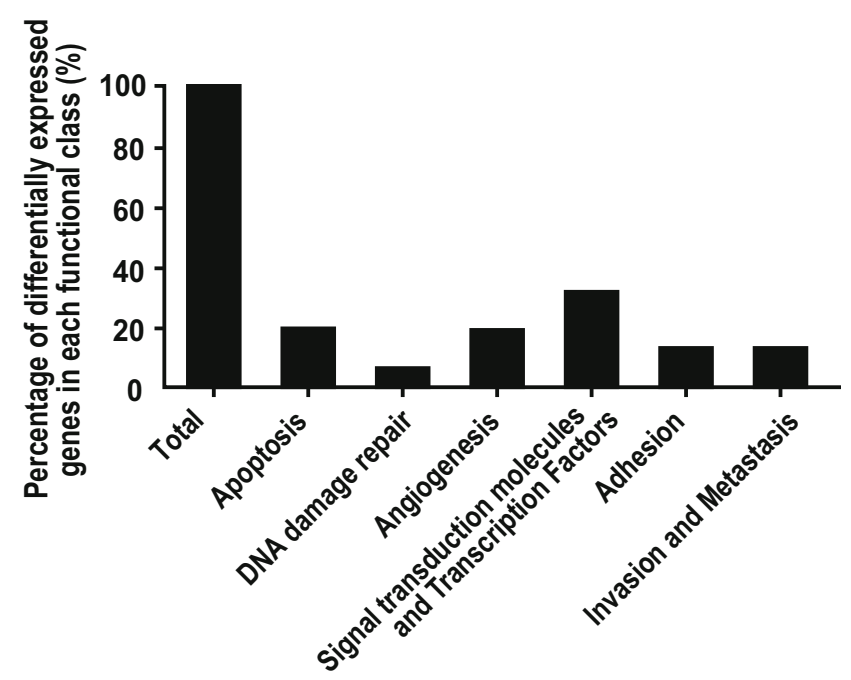

Fig. 1 Genes differentially expressed in response to PCA3 silencing in LNCaP cells. Functional distribution of the identified genes that are differentially expressed in siPCA3-transfected LNCaP cells compared to cells transfected with a scramble sequence. The percentage of differentially expressed cancer-related genes in each functional class is shown. The differentially expressed genes show at least a 2.0 -fold change in PCA3 downregulated LNCaP cells, $p<0.05$ significant differential expression upon PCA3 silencing in LNCaP cells is shown in Online Resource 4. The transcription patterns observed for LNCaP siPCA3-transfected cells indicated the potential role of this IncRNA in modulating the expression of genes related to several acquired capabilities that are required for tumor progression, mainly involving key signal transduction molecules and transcription factors.

\section{PCA3 silencing induces upregulation of AR cofactors}

It has been shown that the activation of AR transcription is regulated through interactions with several cofactors [15]. The significant downregulation of androgen-responsive genes (ARGs) in response to PCA3 silencing, as previously observed by our group [5], led us to ask whether this could be a result of a putative role of PCA 3 in modulating the transcription levels of AR cofactors or their properties to bind to AR. We then analyzed the transcription levels of AR cofactors in response to PCA3 silencing (PCA3 knockdown shown in Online Resource 3) in LNCaP cells, including the AR coactivators ARA 54, ARA 70, ARA 24, CBP, P300, $\beta$-catenin, TIF2, and SRC1 and AR corepressors SMAD 3, SMAD 4, EBP1, cyclin D1, NCoR1, and SMRT (Fig. 2). Among the 14 AR cofactor transcripts tested, nine were significantly upregulated in siPCA3-transfected cells in relation to those transfected with the siScrbl sequence (ARA70, ARA54, CBP, P300, $\beta$-catenin, TIF-2, SRC1, EBP1, and NCoR1) ( $p$ value $\leq 0.05$ ). The other five genes (ARA24, $\beta$-catenin, SMAD 3, SMAD 4, and SMRT) were also upregulated in this experimental condition but did not reach statistical

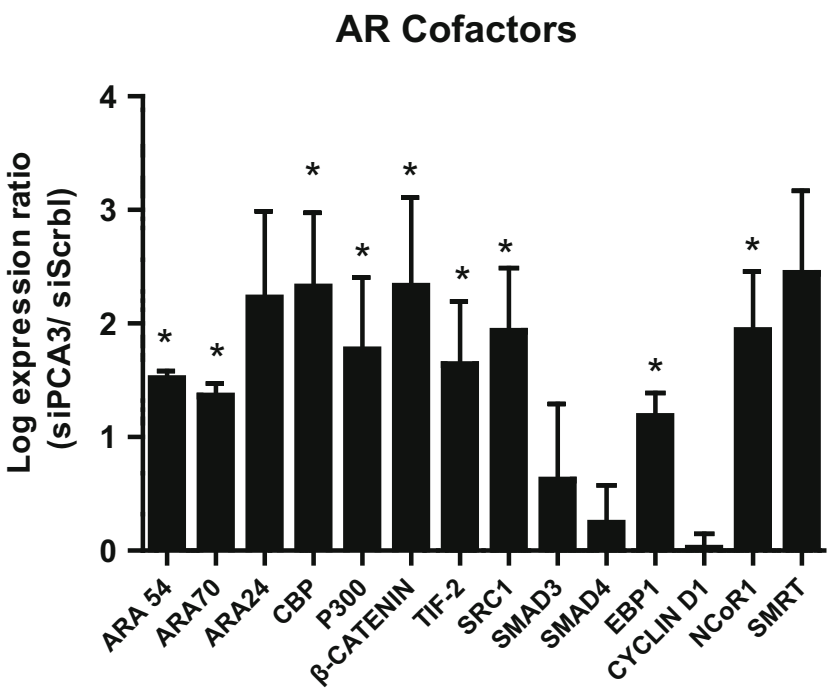

Fig. 2 AR cofactor transcripts are upregulated in siPCA3-transfected LNCaP cells. AR cofactor expression was evaluated in LNCaP cells by qRT-PCR $36 \mathrm{~h}$ after the LNCaP cells were transfected with siPCA3, compared to scrambled-siRNA (siScrbl) transfected cells. Relative gene expression is expressed as the log ratio of siPCa3-and siScrbl-transfected cells. $\beta$-Actin RNA was used as a constitutive gene. Data are shown as mean $\pm \mathrm{SD}(p<0.05)$ 
significance $(p$ value $>0.05)$. These data suggest that the observed upregulated expression of AR cofactor transcripts could be one of the possible mechanisms by which ARGs are negatively modulated in response to PCA3 silencing.

\section{PCA3 downregulation is correlated with a partial reversion in the expression of EMT markers}

While it is an essential process of cellular plasticity for normal tissue and organ development, EMT is also involved in typical features of cancer cell resistance and survival to chemoradiotherapeutic agents [11] and counteracting anoikis [16]. Based on the known AR signaling and EMT cross talks and the involvement of EMT in mediating pro-survival features [9], we investigated how PCA3 downregulation could modulate the expression of EMT markers, in order to provide evidence of involvement of the EMT program in mediating LNCaP cell survival in response to PCA3 silencing. We then tested the transcription levels of EMT epithelial and mesenchymal markers in PCA3-silenced cells. Again, PCA3 silencing for these assays has been validated (Online Resource 3). In response to PCA3 silencing in $\mathrm{LNCaP}$ cells, we observed upregulation of the epithelial markers E-cadherin, Claudin-3, and Cytokeratin-18, while Claudin-4 and Cytokeratin-8 were downregulated, compared to control cells transfected with siScrbl (Fig. 3a). Conversely, analysis of the transcription level of the mesenchymal markers showed that Snail, Twist, and Slug were upregulated, while vimentin was downregulated upon PCA3 silencing (Fig. 3b). Upregulation of E-cadherin, Claudin-3, and Cytokeratin-18 markers and downregulation of Vimentin are characteristics of cells that have lost their survival features, as observed for PCA3-silenced cells. However, this same expression profile was not observed for all epithelial and mesenchymal markers that were tested. For

a

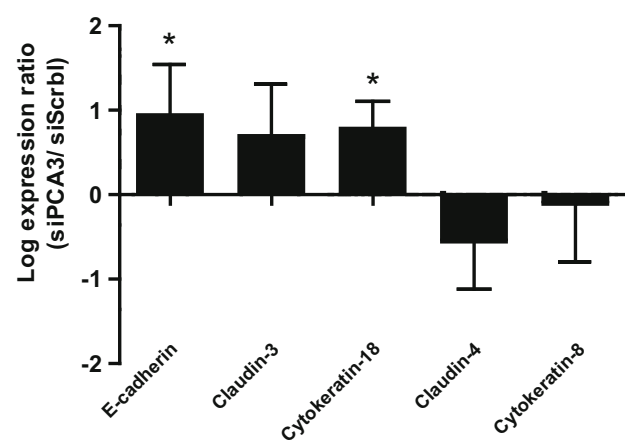

Fig. 3 EMT-related gene expression profile in siPCA3-transfected LNCaP cells. Gene expression profile of epithelial (a) and mesenchymal (b) EMT markers analyzed $36 \mathrm{~h}$ after LNCaP transfection with siPCA3. All experiments were biological replicates, some of these EMT markers, their upregulation or downregulation did not reach statistical significance. Taken together, these analyses of the transcription levels of EMT markers indicated that PCA3 silencing can modulate the expression of some of these EMT markers. PCA3 knockdown does not induce a complete reversion in the expression pattern of epithelial and mesenchymal markers compatible with an involvement of the classical EMT program in mediating the decrease in cell survival in response to PCA3 silencing, as previously observed by our group [5].

\section{Stable PCA3 downregulation in LNCaP cells}

All previously observed phenotypes and gene expression data related to PCA3 silencing were obtained using transient siRNA-based PCA3 downregulation (Figs. 1, 2, and 3). Based on the PCA3 prostate-specific expression and the significant effect of PCA3 transient silencing in negatively modulating LNCaP cell survival [5], we further aimed to develop a strategy to stably downregulate PCA3 and evaluate the effects of this approach on LNCaP viability in a long-term analysis. LNCaP cells were stably transduced with lentiviral vectors and observed over time (116 days) by inverted fluorescence microscopy, as represented in Fig. 4a and FACS at each cell passage (Fig. 4b). Representative FACS dot plots of GFP expression 82 days after $\mathrm{LNCaP}$ cell transduction are shown in Online Resource 5. The percentage of GFP $+\mathrm{LNCaP}$ cells $72 \mathrm{~h}$ after cell transduction was evaluated using an inverted fluorescence microscope, in order to avoid disturbing the cells. For this purpose, we counted the total and the GFP+ cell numbers in five different gates using the Adobe Photoshop CS6 program and then calculated the percentage of GFP+ LNCaP cells (Online Resource 6).

The analysis of GFP+ cells indicated that a significant percentage of cell transduction was obtained for all constructs

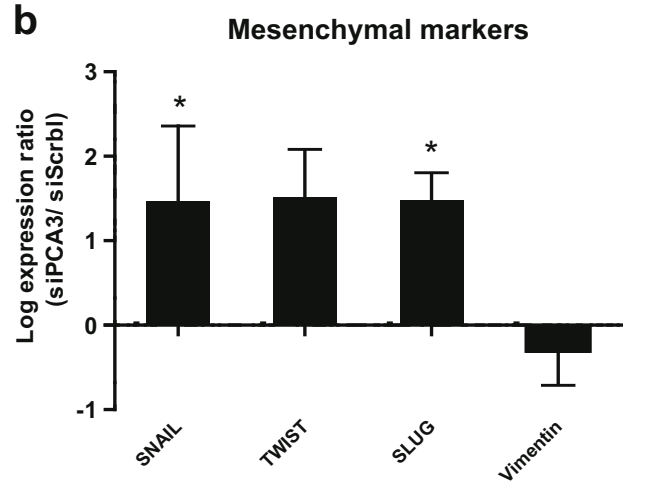

repeated at least three times. $\beta$-Actin RNA was used as a constitutive gene. Relative gene expression is expressed as the log ratio of siPCa3and siScrbl-transfected cells. Data are shown as mean $\pm \operatorname{SD}(p<0.05)$ 


\section{a}

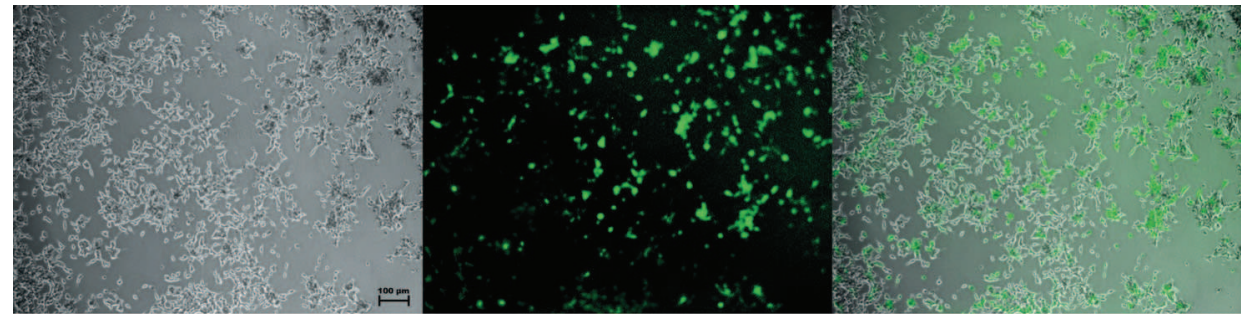

b

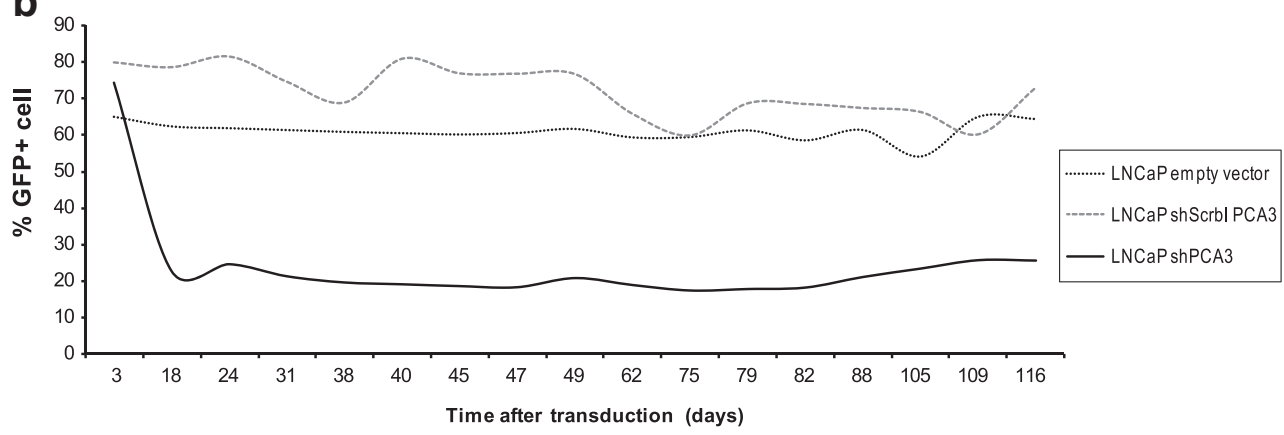

C

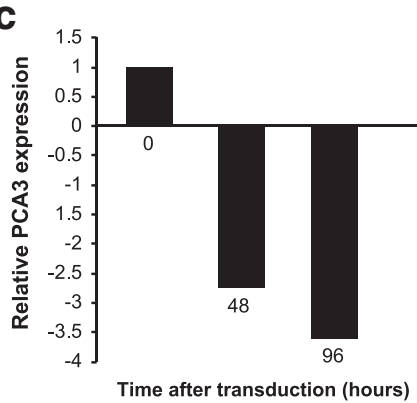

Fig. 4 Evaluation of GFP-positive LNCaP cells over time after cell transduction with lentivirus vector-based shRNAs. a Images $(\times 10)$ of $\mathrm{LNCaP}$ cells acquired by inverted fluorescence microscopy $72 \mathrm{~h}$ after transduction with a lentiviral vector containing the shPCA3 sequence. Left panel: light-field image; middle panel: dark-field fluorescence image; right panel: merge image of dark- and light-field captures. b The $\%$ LNCaP GFP+ cells after transduction with lentivirus vectorbased shRNA were monitored over 116 days and are represented on the graph. Data for day 3 after transduction were obtained by microscopy. All other time points were evaluated by FACS, as shown in Online Resource 5. LNCaP transduced with empty vector (transduction control); $\mathrm{LNCaP}$

used. A reduction of about $60 \%$ of LNCaP GFP+ cells was observed when transduction was carried out with the shPCA3 sequence (Fig. 4b). The reduction in GFP+ cell ratios was far less pronounced when transductions were performed with the shScrbl PCA3 construct or the empty vector (8.6 and $1 \%$, respectively, Fig. 4b). In addition, to further validate the effects of PCA3 stable silencing on LNCaP cell survival, we checked the PCA3 expression levels after cell transduction by qRT-PCR (Fig. 4c). LNCaP cells transduced with lentiviral vectors carrying an shPCA3 showed a 2.74- and 3.61-fold decrease in PCA3 expression levels at 48 and $96 \mathrm{~h}$ after cell transduction, respectively. The number of viable cells was also
shScrbl PCA3 (scramble control) and LNCaP shPCA3 cell (LNCaP cell transduced with lentiviral vector containing a specific shRNA sequence for PCA3). $\mathbf{c}$ Relative PCA3 expression was analyzed by qRT-PCR after cell transduction with lentivirus vector-based shPCA3 (48 and $96 \mathrm{~h}$ ) and is represented on the bar graphs. Data shown represent biological replicates. A representative experiment is shown. d The number of viable cells was analyzed by trypan blue staining exclusion assay, which was evaluated 48,96 , and $144 \mathrm{~h}$ after transduction of LNCaP cells with lentivirus vector-based shPCA3. Data represent biological replicates. A representative experiment is shown

progressively reduced 48 to $144 \mathrm{~h}$ post-transduction after PCA3 stable silencing, but not in control scramble or empty vector conditions (Fig. 4d). These results corroborate the data obtained in the transient silencing with siPCA3, showing a decrease in cell viability after stable PCA3 silencing using lentivirus-based shRNAs.

\section{Discussion}

In order to better comprehend the roles of PCA3 lncRNA in $\mathrm{PCa}$ cell survival and in modulating androgen-related 
signaling, we investigated the expression pattern of several cancer-related genes, including those involved in the EMT program and coding for AR cofactors in response to PCA3 silencing. In addition, based on the known role of PCA3 in modulating PCa cell survival and its possible therapeutic implications [5], we also intended to develop an in vitro strategy to stably silence PCA3 expression.

Our findings revealed that several key cancer-related genes are differentially expressed in LNCaP cells after PCA3 silencing, mainly those that code for gene products mediating transcription control and cell signaling. Notably, we also demonstrated that in response to PCA3 silencing, transcripts coding for AR cofactors are mainly upregulated, while EMT transcription levels are differentially modulated in these conditions. Furthermore, we were able to develop an efficient in vitro system in which stable silencing of PCA3 was achieved by transducing $\mathrm{LNCaP}$ cells with a lentiviral vector containing an shRNA specifically targeting PCA3, also resulting in a significant and long-term decrease in LNCaP cell survival.

In addition to providing data regarding the transcription patterns associated with PCA3 silencing in the androgenresponsive $\mathrm{LNCaP}$ PCa cells, our results may indicate additional mechanisms by which this and other prostate lncRNAs may modulate the survival of prostate tumor cells and tumor progression. Recently, other PCa lncRNAs have been correlated with AR signaling, such as PCGEM1 [17], PRNCR1 [18], growth-arrest-specific five (GAS5) [19], PCAT29 [20], and Linc00963 [21]. The present report and a previous publication from our group [5] have expanded the available information on the mechanisms that possibly modulate the expression of AR and androgen-responsive genes (ARGs), mediated by an IncRNA that is specifically expressed in PCa cells.

As one of the approaches to further understand the different cellular pathways by which PCA3 can affect cell survival, we surveyed the gene expression patterns related to PCA3 silencing. Of the 84 key cancer-related genes tested, 16 were significantly differentially expressed in LNCaP cells in which PCA3 had been silenced. Notably, most of these differentially expressed transcripts correspond to gene products involved in the control of gene expression. Other noncoding RNAs (ncRNAs), especially long ncRNA molecules, are also involved in controlling gene expression, especially in cancer cells $[12,13]$. Our data suggest that the lncRNA PCA3 can also behave as a modulator of transcription control. In agreement with our hypothesis, a recent report described PCA3 as a dominant-negative oncogene, controlling PRUNE2 levels through a regulatory mechanism involving the formation of a PRUNE2/PCA3 double-stranded RNA that undergoes adenosine deaminase acting on RNA (ADAR)-dependent adenosine-to-inosine RNA editing [22]. Other lncRNAs, such as HOTAIR, PRNCR1, and PCGEM1, have also been reported to be involved in the control of cancer-related gene expression [23] and in regulating the expression of AR target genes and cancer cell proliferation [13]. The differentially expressed genes reported here have known roles as modulators of cell survival, especially ERRB2 [23], PI3K [24], VEGF [25], and TERT [26]. Furthermore, some of these genes can regulate AR signaling, such as BRCA [27], ERBB2 [28], FOS [29], PI3K [30], BAD [31], TERT [32], and PLAUR [33]. A similar approach demonstrated a PCGEM1-associated gene expression signature that was significantly repressed in response to androgen ablation therapy and in hormone-refractory versus hormone-naive PCa patients [17]. Another recent report investigating a metabolic generelated pathway showed that PCGEM1 reprograms the androgen network in a tumor-specific way [34]. Further experimental validation should be conducted to explore the role of these differentially expressed genes and their PCA3-related roles in modulating LNCaP cell survival and AR signaling.

When knocking down PCA3 using a specific siRNA molecule that specifically targets PCA3, we observed the upregulation of several transcripts that code for AR cofactors. We hypothesized that one of the molecular mechanisms by which PCA3 could modulate the expression of ARGs, as we demonstrated previously [5], may be by controlling the expression levels of AR cofactors. Our data supported our hypothesis, suggesting that PCA3 could be a negative modulator of the transcription levels of $\mathrm{AR}$ cofactors. If it suppresses the expression of AR cofactors, PCA 3 could be a key element in the transcription apparatus that regulates the expression of the ARGs. However, the precise molecular mechanism by which PCA3 could perform this role needs further investigation. Moreover, the protein expression levels of AR cofactors should be determined. Several studies have indicated that the transcription activity of AR itself is modulated by AR cofactors that promote or suppress AR transactivation [35]. Of the AR cofactors tested here, ARA 54, ARA 70, ARA 24, CBP, $\mathrm{P} 300, \beta$-catenin, TIF2, and SRC1 are AR coactivators. It seems paradoxical in our data that AR coactivators are also upregulated upon PCA3 silencing, while ARGs are downregulated in this experimental condition [5]. Similar conflicting data have been reported previously, in which overexpression of two AR corepressors, NCoR and SMRT, did not inhibit AR-dependent gene expression in PCa cell lines but rather activated the expression of ARGs [36]. A recent report demonstrated that changes in the expression levels or cellular location of specific AR cofactors may play a crucial role in the switch between their roles as activators or repressors of $A R$ target gene programs, such as cell proliferation [37]. Since, in our model, both coactivators and corepressors are overexpressed in response to PCA3 knockdown, it is also possible that this expression pattern could affect the appropriate binding activities between AR and their corresponding AR cofactors, triggering the downregulation of ARGs. In accordance with this hypothesis, it has been suggested that aberrant 
cofactor activity due to mutations or altered expression levels may be a contributing factor to PCa progression. In this situation, we speculate whether PCA3 could behave as an AR modulator, by affecting AR activity, AR and their cofactor interactions, or the expression patterns of AR cofactors, as has been proposed for the CTBP1-AS IncRNAs [38]. In support of our proposals, other authors have reported that ncRNAs are able to modulate AR signaling through their cofactors, such as miR-125b [39]. Further studies should functionally demonstrate whether PCA3 can modulate the binding activities of $\mathrm{AR}$ and $\mathrm{AR}$ cofactors and their corresponding molecular mechanisms.

In the present study, we also aimed to test whether the classical EMT program could be among the mechanisms by which PCA3 modulates PCa cell survival. Upon PCA3 silencing, we did not observe a classical reversion in the expression of EMT markers, with a corresponding upregulation of EMT epithelial markers and downregulation of EMT mesenchymal markers, compatible with cell phenotypes losing their survival features [9]. In our experimental model, the EMT epithelial markers E-cadherin, Claudin-3, and Cytokeratin-18 were upregulated, but not Claudin-4 and Cytokeratin-8, which were downregulated in this experimental condition. Correspondingly, the EMT mesenchymal markers Snail, Twist, and Slug were upregulated, while only vimentin was downregulated. Based on these results, we speculate that our data are in accordance with the putative role of PCA3 as a modulator of $\mathrm{LNCaP}$ cell survival, by a partial contribution to EMT signaling. In many development or disease processes, including cancer, cells do not acquire all the features associated with EMT, leading to what we refer to as partial EMT (pEMT) [39]. In some metastatic tissues, tumors with decreased levels of vimentin expression have been observed, although this has been generally described as an overexpressed mesenchymal marker in metastatic tissues [9]. Metastatic PCa tissues that overexpress E-cadherin, compared to nontumor primary specimens, have also been reported. Similarly, a partial reversion of classical EMT, also termed mesenchymal-to-epithelial reverting transition (MErT), has also been described. MErT has been characterized by the persistence in the expression of mesenchymal markers and the de novo expression of only some epithelial markers [40]. In PCA3-silenced cells, our data accord with a pattern similar to a MErT process. The differential expression of these different EMT markers observed in the present study could also individually regulate survival. Aberrant expression of Ecadherin and Snail, for instance, has been correlated with tumor cell survival $[5,41]$. Hence, we propose that PCA3 could modulate the expression of some EMT markers, possibly through a mechanism similar to pEMT/MErT or alternatively by modulating the expression of individualEMT markers, which per se could control cell survival. The protein expression of these EMT markers should be further investigated to better determine the putative involvement of these markers in LNCaP cell survival and the role of PCA 3 in this process.
In this study, we also constructed a lentivirus vector that efficiently silenced PCA3 in a long-term analysis and led to the decrease in viability of cells transduced with the transgene. These results concord with previous data from our group in which PCA3 transient knockdown also decreased cell survival [5]. These data indicate a potential application of PCA3 as a therapeutic target in $\mathrm{PCa}$, especially for castration-resistant prostate cancer (CRPC), for which no effective treatment is available. In CRPC, several mechanisms contribute to resistance to androgen deprivation therapy, such as AR gene amplifications and mutations, alternative signaling pathways that can activate the expression of ARGs irrespective of AR activation, and also androgen synthesis by PCa cells [6]. As previously observed by our group [5], PCA3 knockdown inhibited the expression of all ARGs tested, even under $5 \alpha$-dihydrotestosterone (DHT) treatment, indicating that the final effect of PCA3 downregulation may be stronger than the effect of DHT stimulation in modulating the expression of these target genes. On the other hand, we also have shown that Akt and ERK protein phosphorylation levels remained unchanged in siPCA3-transfected cells, indicating that at least these alternative pathways that are also able to activate AR, irrespective of ligand activation, were not altered after PCA3 knockdown [5]. Taken together, these data provide evidence that a role of PCA3 in modulating the expression of these ARGs may function downstream from and irrespectively of AR activation. Also supporting this hypothesis, we observed that the downregulation of these ARGs occurred even in LNCaP cells that were not DHT-activated. In view of our data and based on our previous report, we propose that silencing PCA 3 could be an alternative approach to inhibit some of these known mechanisms related to CRPC. Some reports have also shown that stable AR silencing led to a significant decrease in serum PSA and in tumor growth. These authors also observed a delay in the progression of a PCa tumor from a primary prostate tumor to a CRPC disease and tumor regression [44]. Considering several molecular mechanisms that can provide resistance of CRPC to anti-androgenic treatment approaches, we propose strategies aiming to stably silence PCA3 in order to maintain ARG downregulation, which might increase the efficacy of CRPC treatment approaches. Some reports have also shown that stable AR silencing led to a significant decrease in serum PSA and in tumor growth. These authors also observed a delay in the progression of a $\mathrm{PCa}$ tumor from a primary prostate tumor to a CRPC disease and tumor regression [44]. Considering several molecular mechanisms that can provide resistance of CRPC to several antiandrogenic treatment approaches, we propose strategies aiming to stably silence PCA3 in order to maintain ARG downregulation, which might increase the efficacy of CRPC growth inhibition. Moreover, the construction of this shPCA3 cassette incorporated into this lentivirus vector opens possibilities for targeting PCA3 in vivo in animal models. Overall, our 
data indicated that gene expression patterns in response to PCA3 silencing provide evidence that this lncRNA could modulate the expression of several key cancer-related genes, especially those modulating the control of gene expression, as well as AR cofactors and individual EMT markers. These data could contribute to a better understanding, not only of the role of PCA3 in PCa cells, but also of additional and still-unknown mechanisms by which lncRNAs can control cell survival and tumor progression. By developing an in vitro system to stably downregulate PCA3, we can propose an experimental model to further test PCA3 silencing as a possible therapeutic approach to control the survival of PCa cells.

Acknowledgments This study was supported by grants from the Fundação de Amparo à Pesquisa do Rio de Janeiro (FAPERJ), Conselho Nacional de Desenvolvimento Científico e Tecnológico (CNPq), Instituto Nacional de Ciência e Tecnologia (INCT) para Controle do Câncer, Coordenação de Aperfeiçoamento de Pessoal de Nível Superior (CAPES), Ministério da Saúde (MS)/Fundação do Câncer, Instituto Nacional de Câncer (INCa), Fundação Oswaldo Cruz (FIOCRUZ)/Bio-Manguinhos, and Swiss Bridge Foundation. We are especially grateful to Dr. Marcos Freire and Dr. Marco Medeiros for kindly supporting this study. We also thank Dr. Marcelo Ribeiro Alves for his kind support with statistical analyses.

Conflicts of interest None

\section{References}

1. De Kok JB, Verhaegh GW, Roelofs RW, Hessels D, Kiemeney LA, Aalders TW, et al. DD3(PCA3), a very sensitive and specific marker to detect prostate tumors. Cancer Res. 2002;62:2695-8.

2. Bussemakers MJ, van Bokhoven A, Verhaegh GW, Smit FP, Karthaus HF, Schalken JA, et al. DD3: a new prostate-specific gene, highly overexpressed in prostate cancer. Cancer Res. 1999;59:5975-9.

3. Clarke RA, Zhao Z, Guo A-Y, Roper K, Teng L, Fang Z-M, et al. New genomic structure for prostate cancer specific gene PCA3 within BMCC1: implications for prostate cancer detection and progression. PLoS One. 2009;4:e4995.

4. Van Bokhoven A, Varella-Garcia M, Korch C, Johannes WU, Smith EE, Miller HL, et al. Molecular characterization of human prostate carcinoma cell lines. Prostate. 2003;57:205-25.

5. Ferreira LB, Palumbo A, de Mello KD, Sternberg C, Caetano MS, de Oliveira FL, et al. PCA3 noncoding RNA is involved in the control of prostate-cancer cell survival and modulates androgen receptor signaling. BMC Cancer. 2012;12:507.

6. Schaeffer EM, Marchionni L, Huang Z, Simons B, Blackman A, Yu $\mathrm{W}$, et al. Androgen-induced programs for prostate epithelial growth and invasion arise in embryogenesis and are reactivated in cancer. Oncogene. 2008;27:7180-91.

7. Feldman BJ, Feldman D. The development of androgenindependent prostate cancer. Nat Rev Cancer. 2001;1:34-45.

8. Matuszak EA, Kyprianou N. Androgen regulation of epithelialmesenchymal transition in prostate tumorigenesis. Expert Rev Endocrinol Metab. 2011;6:469-82.

9. Li P, Yang R, Gao W-Q. Contributions of epithelial-mesenchymal transition and cancer stem cells to the development of castration resistance of prostate cancer. Mol Cancer. 2014;13:55.
10. Sabbah M, Emami S, Redeuilh G, Julien S, Prévost G, Zimber A, et al. Molecular signature and therapeutic perspective of the epithelial-to-mesenchymal transitions in epithelial cancers. Drug Resist Update Rev Comment Antimicrob Anticancer Chemother. 2008;11:123-51.

11. Nantajit D, Lin D, Li JJ. The network of epithelial-mesenchymal transition: potential new targets for tumor resistance. J. Cancer Res Clin Oncol. 2014.

12. Angrand P-O, Vennin C, Le Bourhis X, Adriaenssens E. The role of long non-coding RNAs in genome formatting and expression. Front Genet. 2015;6:165.

13. Yang L, Lin C, Jin C, Yang JC, Tanasa B, Li W, et al. IncRNAdependent mechanisms of androgen-receptor-regulated gene activation programs. Nature. 2013;500:598-602.

14. Bonamino M, Serafini M, D'Amico G, Gaipa G, Todisco E, Bernasconi S, et al. Functional transfer of CD40L gene in human B-cell precursor ALL blasts by second-generation SIN lentivectors. Gene Ther. 2004;11:85-93.

15. Sung YY, Cheung E. Androgen receptor co-regulatory networks in castration-resistant prostate cancer. Endocr Relat Cancer. 2014;21: R1-11.

16. Paoli P, GiannoniE, ChiarugiP. Anoikis molecularpathways and its role in cancer progression. Biochim Biophys Acta. 1833;2013:3481-98.

17. Parolia A, Crea F, Xue H, Wang Y, Mo F, Ramnarine VR, et al. The long non-coding RNA PCGEM1 is regulated by androgen receptor activity in vivo. Mol Cancer. 2015;14:46.

18. Prensner JR, Sahu A, Iyer MK, Malik R, Chandler B, Asangani IA, et al. The lncRNAs PCGEM1 and PRNCR1 are not implicated in castration resistant prostate cancer. Oncotarget. 2014;5:1434-8.

19. Yacqub-Usman K, Pickard MR, Williams GT. Reciprocal regulation of GAS5 1 ncRNA levels and mTOR inhibitor action in prostate cancer cells. Prostate. 2015;75:693-705.

20. Malik R, Patel L, Prensner JR, Shi Y, Iyer MK, Subramaniyan S, et al. The lncRNA PCAT29 inhibits oncogenic phenotypes in prostate cancer. Mol Cancer Res. 2014;12:1081-7.

21. Wang L, Han S, Jin G, Zhou X, Li M, Ying X, et al. Linc00963: a novel, long non-coding RNA involved in the transition of prostate cancer from androgen-dependence to androgen-independence. Int $\mathrm{J}$ Oncol. 2014;44:2041-9.

22. Salameh A, Lee AK, Cardó-Vila M, Nunes DN, Efstathiou E, Staquicini FI, et al. PRUNE2 is a human prostate cancer suppressor regulated by the intronic long noncoding RNA PCA3. Proc Natl Acad Sci U S A. 2015;112:8403-8.

23. Grabinski N, Ewald F. Ibrutinib (ImbruvicaTM) potently inhibits ErbB receptor phosphorylation and cell viability of ErbB2-positive breast cancer cells. Invest New Drugs. 2014;32:1096-104.

24. Dubrovska A, Kim S, Salamone RJ, Walker JR, Maira S-M, GarcíaEcheverría C, et al. The role of PTEN/Akt/PI3K signaling in the maintenance and viability of prostate cancer stem-like cell populations. Proc Natl Acad Sci U S A. 2009;106:268-73.

25. Knizetova P, Ehrmann J, Hlobilkova A, Vancova I, Kalita O, Kolar $\mathrm{Z}$, et al. Autocrine regulation of glioblastoma cell cycle progression, viability and radioresistance through the VEGF-VEGFR2 (KDR) interplay. Cell Cycle Georget Tex. 2008;7:2553-61.

26. Wang C-M, Jia Z-J, Zheng R-L. The effect of 17 sesquiterpenes on cell viability and telomerase activity in the human ovarian cancer cell line HO-8910. Planta Med. 2007;73:180-4.

27. Li AJ, McAllister P, Karlan BY. Impact of androgen receptor cytosine-adenine-guanine polymorphisms on clinical outcome in BRCA mutation-associated epithelial ovarian cancers. Gynecol Oncol. 2010;116:105-8.

28. Hammarsten P, Winther J, Rudolfsson SH, Häggström J, Karalija A, Egevad L, et al. ErbB2 receptor immunoreactivity in prostate cancer: relationship to the androgen receptor, disease severity at diagnosis and disease outcome. PLoS One. 2014;9:e105063. 
29. Tillman K, Oberfield JL, Shen XQ, Bubulya A, Shemshedini L. cFos dimerization with c-Jun represses c-Jun enhancement of androgen receptor transactivation. Endocrine. 1998;9:193-200.

30. Liu L, Dong X. Complex impacts of PI3K/AKT inhibitors to androgen receptor gene expression in prostate cancer cells. PLoS One. 2014;9:e108780

31. Papadopoulou N, Charalampopoulos I, Anagnostopoulou V, Konstantinidis G, Föller M, Gravanis A, et al. Membrane androgen receptor activation triggers down-regulation of $\mathrm{PI}-3 \mathrm{~K} / \mathrm{Akt} / \mathrm{NF}$ kappaB activity and induces apoptotic responses via Bad, FasL and caspase-3 in DU145 prostate cancer cells. Mol Cancer. 2008;7:88.

32. Moehren U, Papaioannou M, Reeb CA, Grasselli A, Nanni S, Asim $\mathrm{M}$, et al. Wild-type but not mutant androgen receptor inhibits expression of the hTERT telomerase subunit: a novel role of AR mutation for prostate cancer development. FASEB J Off Publ Fed Am Soc Exp Biol. 2008;22:1258-67.

33. Pentyala SN, Whyard TC, Waltzer WC, Meek AG, Hod Y. Androgen induction of urokinase gene expression in $\mathrm{LNCaP}$ cells is dependent on their interaction with the extracellular matrix. Cancer Lett. 1998;130:121-6.

34. Hung C-L, Wang L-Y, Yu Y-L, Chen H-W, Srivastava S, Petrovics $\mathrm{G}$, et al. A long noncoding RNA connects c-Myc to tumor metabolism. Proc Natl Acad Sci U S A. 2014;111:18697-702.
35. Wang D, Tindall DJ. Androgen action during prostate carcinogenesis. Methods Mol Biol. 2011;776:25-44. Clifton NJ.

36. Laschak M, Bechtel M, Spindler K-D, Hessenauer A. Inability of NCoR/SMRT to repress androgen receptor transcriptional activity in prostate cancer cell lines. Int J Mol Med. 2011;28:645-51.

37. Daniels G, Jha R, Shen Y, Logan SK, Lee P. Androgen receptor coactivators that inhibit prostate cancer growth. Am J Clin Exp Urol. 2014;2:62-70.

38. Liu Z, Hao C, Song D, Zhang N, Bao H, Qu Q. androgen receptor coregulator CTBP1-as is associated with polycystic ovary syndrome in Chinese women: a preliminary study. Reprod Sci. Thousand Oaks Calif. 2014.

39. Yang X, Bemis L, Su L-J, Gao D, Flaig TW. miR-125b regulation of androgen receptor signaling via modulation of the receptor complex co-repressor NCOR2. Biores Open Access. 2012;1:55-62.

40. Chao Y, Wu Q, Acquafondata M, Dhir R, Wells A. Partial mesenchymal to epithelial reverting transition in breast and prostate cancer metastases. Cancer Microenviron Off J Int Cancer Microenviron Soc. 2012;5:19-28.

41. Inge LJ, Barwe SP, D’Ambrosio J, Gopal J, Lu K, Ryazantsev S, et al. Soluble E-cadherin promotes cell survival by activating epidermal growth factor receptor. Exp Cell Res. 2011;317:838-48. 
Online Resource 1 Oligonucleotides sequences used for analysis of EMT markers and AR cofactors transcripts expression by qRT-PCR.

\begin{tabular}{|c|c|}
\hline Oligonucleotide sequence name & Oligonucleotide sequence $5^{\prime} \rightarrow 3^{\prime}$ \\
\hline E-cadherin $\mathrm{F}$ & 5' GAATGACAACAAGCCCGAAT 3' \\
\hline E-cadherin $\mathrm{R}$ & 5' GACCTCCATCACAGAGGTTCC 3' \\
\hline Cytokeratin-8 F & 5' GCTGACCGACGAGATCAACT 3' \\
\hline Cytokeratin-8 R & 5' CATGGACAGCACCACAGATG 3' \\
\hline Cytokeratin-18 F & 5' GCGAGAAGGAGACCATGCA 3' \\
\hline Cytokeratin-18 R & 5' GGTGTTCCCGGATTTTTGATCT 3' \\
\hline Claudin-3 F & 5' CTGCTCTGCTGCTCGTGTCC 3' \\
\hline Claudin-3 R & 5' TTAGACGTAGTCCTTGCGGTCGTAG3' \\
\hline Claudin-4 F & 5' GGCTGCTTTGCTGCAACTGTC 3' \\
\hline Claudin-4 R & 5' GAGCCGTGGCACCTTACACG 3' \\
\hline Vimentin F & 5' GACAATGCGTCTCTGGCACGTCTT 3' \\
\hline Vimentin R & 5' TCCTCCGCCTCCTGCAGGTTCTT 3' \\
\hline Twist $\mathrm{F}$ & 5' CCCAACTCCCAGACACCTC $3^{\prime}$ \\
\hline Twist $R$ & 5' CAAAAAGAAAGCGCCCAAC $3^{\prime}$ \\
\hline Snail F & 5' TTCCAGCAGCCCTACGACCAG 3' \\
\hline Snail $R$ & 5' CTTTCCCACTGTCCTCATC 3' \\
\hline Slug $\mathrm{F}$ & 5' TGGTTGCTTCAAGGACACAT 3' \\
\hline Slug $R$ & 5' GTTGCAGTGAGGGCAAGAA 3' \\
\hline$\beta$-actin $F$ & 5' TGACCCAGATCATGTTTGAGA 3' \\
\hline$\beta$-actin $\mathrm{R}$ & 5’ ACTCCATGCCCAGGAAGGA 3' \\
\hline ARA70 F & 5' ACAATTACTCTGCGCCAGACCA 3' \\
\hline ARA70 R & 5' GCTGAACTAGCATGAGCCATCAA 3' \\
\hline ARA54 F & 5’ AGAGATGGAAAGTAAGGAGTG 3' \\
\hline ARA54 R & 5' GACGGAAGATTAGGGAAAAAC 3' \\
\hline ARA24 F & 5' CCACCAGAAGTTGTCATGGAC 3' \\
\hline ARA24 R & 5' ACAAGGGATGAGTTCACTTGC 3' \\
\hline P300 F & 5' CGCTTTGTCTACACCTGCAA 3' \\
\hline P300 R & 5' TGCTGGTTGTTGCTCTCATC 3' \\
\hline CBP F & 5' CACCAGCAGATGAGGACTCT 3' \\
\hline CBP R & 5' TACACCGGTGCTAGGAGGAG 3' \\
\hline$\beta$-catenin $F$ & 5' AATACCATCCATTGTTTGTGCAG 3' \\
\hline$\beta$-catenin $\mathrm{R}$ & 5' AGCTCAACTGAAAGCCGTTT 3' \\
\hline TIF2 F & 5' TAATGCACAGATGCTGGCC $3^{\prime}$ \\
\hline TIF2 R & 5' TCTGTGTATGTGCCATTCGG 3' \\
\hline SRC1 F & 5' ATGGTGAGCAGAGGCATGACA 3' \\
\hline SRC1 R & 5' AAACGGTGATGCTCATGTTG 3' \\
\hline SMRT F & 5' AGGAGGAGAAAGATGAGAAGGA 3' \\
\hline SMRT R & 5' TCTTCTCCTTGAGGAGGTCTT 3' \\
\hline NCoR1 F & 5' GGCCCTCTTCAGTCTCCTCT 3' \\
\hline NCoR1 R & 5' GGCAGGTTTTTTGACCTGCTA 3' \\
\hline EBP1 F & 5' AGCGACCAGGATTATATTCTCAAG 3' \\
\hline EBP1 $R$ & 5' ATAACATCTGCTTTCCTCCCTG 3' \\
\hline Ciclyn D1 F & 5' TCTACACCGACAACTCCATCCG 3' \\
\hline Ciclyn D1 R & 5' TCTGGCATTTTGGAGAGGAAGTG 3' \\
\hline Smad $3 \mathrm{~F}$ & 5' CCCCAGCACATAATAACTTGG 3' \\
\hline Smad $3 \mathrm{R}$ & 5' AGGAGATGGAGCACCAGAAG 3' \\
\hline Smad $4 \mathrm{~F}$ & 5' TTGCTTCCACTTGAATGCTG 3' \\
\hline Smad $4 \mathrm{R}$ & 5' CTTCAAAGGGGACACCAAAA 3' \\
\hline
\end{tabular}

-Article Title: PCA3 long non-coding RNA modulates the expression of key cancer-related genes in LNCaP prostate cancer cells.

-Journal Name: Tumor Biology

-Authors names: Ana Emília Goulart Lemos, Luciana Bueno Ferreira, Nadia Maria Batoreu, Paula Priscilla de Freitas, Martin Hernan Bonamino, Etel Rodrigues Pereira Gimba

-Affiliation of the Corresponding author (Etel Rodrigues Pereira Gimba):

Instituto Nacional de Câncer José Alencar Gomes da Silva, Rio de Janeiro, Brazil and Universidade Federal Fluminense, Rio de Janeiro, Brazil

-E-mail Address of the Corresponding author: etelgimba@id.uff.br 
Online Resource 2 PCA3 shRNA specific sequence and Scramble shRNA sequence used for PCA3 stable downregulation.

\begin{tabular}{ll}
\hline shRNA sequence name & shRNA sequence 5' $\rightarrow 33^{\prime}$ \\
\hline \multirow{2}{*}{ shPCA3 $\mathrm{F}$} & $\begin{array}{l}\text { 5' CGCGTCCCCCCACAATATGCATAAATCTAACTCCTTCAA } \\
\text { GAGAGGAGTTAGATTTATGCATATTGTGGTTTTTGGAAAT 3' }\end{array}$ \\
\hline \multirow{2}{*}{ shPCA3 R } & 5' CGATTTCCAAAAACCACAATATGCATAAATCTAACTCCT \\
& CTCTTGAAGGAGTTAGATTTATGCATATTGTGGGGGGA 3' \\
\hline \multirow{2}{*}{ shScrbI PCA3 F } & 5' CGCGTCCCCGACCCATACTTACCTAACAAACTATTTCAA \\
& GAGAATAGTTTGTTAGGTAAGTATGGGTCTTTTTGGAAT 3' \\
\hline \multirow{2}{*}{ shScrbI PCA3 R } & 5' CGATTTCCAAAAAGACCCATACTTACCTAACAAACTATT \\
& CTCTTGAAATAGTTTGTTAGGTAAGTATGGGTCGGGGA 3' \\
\hline
\end{tabular}

-Article Title: PCA3 long non-coding RNA modulates the expression of key cancer-related genes in LNCaP prostate cancer cells.

-Journal Name: Tumor Biology

-Authors names: Ana Emília Goulart Lemos, Luciana Bueno Ferreira, Nadia Maria Batoreu, Paula Priscilla de Freitas, Martin Hernan Bonamino, Etel Rodrigues Pereira Gimba

-Affiliation of the Corresponding author (Etel Rodrigues Pereira Gimba):

Instituto Nacional de Câncer José Alencar Gomes da Silva, Rio de Janeiro, Brazil and Universidade Federal Fluminense, Rio de Janeiro, Brazil

-E-mail Address of the Corresponding author: etelgimba@id.uff.br 

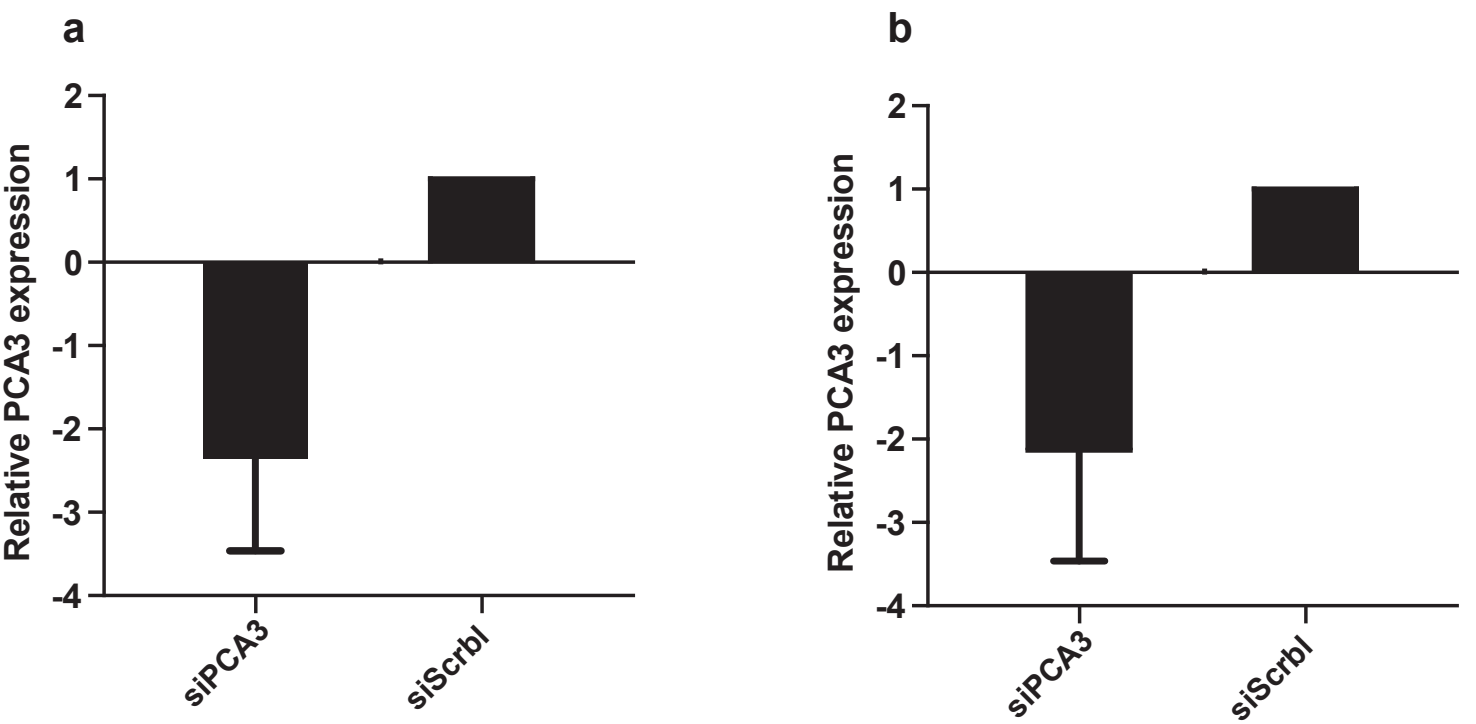

-Article Title: PCA3 long non-coding RNA modulates the expression of key cancer-related genes in LNCaP prostate cancer cells.

-Journal Name: Tumor Biology

-Authors names: Ana Emília Goulart Lemos, Luciana Bueno Ferreira, Nadia Maria Batoreu, Paula

Priscilla de Freitas, Martin Hernan Bonamino, Etel Rodrigues Pereira Gimba

-Affiliation of the Corresponding author (Etel Rodrigues Pereira Gimba):

Instituto Nacional de Câncer José Alencar Gomes da Silva, Rio de Janeiro, Brazil and Universidade

Federal Fluminense, Rio de Janeiro, Brazil

-E-mail Address of the Corresponding author: etelgimba@id.uff.br 
Online Resource 4 Genes differentially expressed in response to PCA3 downregulation in LNCaP cells.

\begin{tabular}{|c|c|c|c|c|c|}
\hline Function & Gene & GenBank\# (RefSeq) & Gene Name & Fold & p-value \\
\hline \multirow{5}{*}{$\begin{array}{l}\text { Signal transduction } \\
\text { molecules and } \\
\text { transcription factors }\end{array}$} & ERBB2 & NM_004448 & $\begin{array}{c}\text { V-erb-b2 erythroblastic } \\
\text { leukemia viral oncogene } \\
\text { homolog } 2, \\
\text { neuro/glioblastoma } \\
\text { derived oncogene } \\
\text { homolog (avian) }\end{array}$ & 3,63 & $4.1 \mathrm{E}-3$ \\
\hline & FOS & NM_005252 & $\begin{array}{l}\text { V-fos FBJ murine } \\
\text { osteosarcoma viral } \\
\text { oncogene homolog }\end{array}$ & $-2,72$ & $4.2 \mathrm{E}-3$ \\
\hline & JUN & NM_002228 & Jun oncogene & 2,32 & $1.5 \mathrm{E}-2$ \\
\hline & MAP2K1 & NM_002755 & $\begin{array}{c}\text { Mitogen-activated } \\
\text { protein kinase kinase } 1\end{array}$ & $-4,5$ & $1.6 \mathrm{E}-2$ \\
\hline & PIK3R1 & NM_181504 & $\begin{array}{l}\text { Phosphoinositide-3- } \\
\text { kinase, regulatory } \\
\text { subunit } 1 \text { (alpha) }\end{array}$ & 2,99 & $2.5 \mathrm{E}-4$ \\
\hline \multirow{3}{*}{ Angiogenesis } & VEGFA & NM_003376 & $\begin{array}{l}\text { Vascular endothelial } \\
\text { growth factor A }\end{array}$ & 2,24 & $9.2 \mathrm{E}-4$ \\
\hline & COL18A1 & NM_030582 & $\begin{array}{c}\text { Collagen, type XVIII, } \\
\text { alpha } 1\end{array}$ & 2,46 & $3.0 \mathrm{E}-2$ \\
\hline & IFNB1 & NM_002176 & $\begin{array}{c}\text { Interferon, beta } 1, \\
\text { fibroblast }\end{array}$ & $-2,48$ & $8.4 \mathrm{E}-4$ \\
\hline \multirow{3}{*}{$\begin{array}{l}\text { Apoptosis and Cell } \\
\text { Senescence }\end{array}$} & $\mathrm{BAD}$ & NM_004322 & $\begin{array}{c}\text { BCL2-associated } \\
\text { agonist of cell death }\end{array}$ & 2,21 & $3.6 \mathrm{E}-2$ \\
\hline & TERT & NM_198253 & $\begin{array}{c}\text { Telomerase reverse } \\
\text { transcriptase }\end{array}$ & $-3,55$ & $3.9 \mathrm{E}-5$ \\
\hline & TNFRSF25 & NM_003790 & & & \\
\hline \multirow{2}{*}{$\begin{array}{l}\text { Invasion and } \\
\text { metastasis }\end{array}$} & MTA2 & NM_004739 & $\begin{array}{l}\text { Metastasis associated } 1 \\
\text { family, member } 2\end{array}$ & 2,77 & $4.4 \mathrm{E}-2$ \\
\hline & PLAUR & NM_002659 & $\begin{array}{l}\text { Plasminogen activator, } \\
\text { urokinase receptor }\end{array}$ & $-2,23$ & $3.5 \mathrm{E}-2$ \\
\hline \multirow[t]{2}{*}{ Adhesion } & ITGB1 & NM_002211 & $\begin{array}{l}\text { Integrin, beta } 1 \\
\text { (fibronectin receptor, } \\
\text { beta polypeptide, } \\
\text { antigen CD29 includes } \\
\text { MDF2, MSK12) }\end{array}$ & 2,09 & $4.9 \mathrm{E}-4$ \\
\hline & MTSS1 & NM_014751 & Metastasis suppressor 1 & 3,08 & $4.2 \mathrm{E}-2$ \\
\hline DNA damage repair & BRCA1 & NM_007294 & $\begin{array}{c}\text { Breast cancer 1, early } \\
\text { onset }\end{array}$ & $-2,78$ & $3.3 \mathrm{E}-3$ \\
\hline
\end{tabular}

-Article Title: PCA3 long non-coding RNA modulates the expression of key cancer-related genes in LNCaP prostate cancer cells.

-Journal Name: Tumor Biology

-Authors names: Ana Emília Goulart Lemos, Luciana Bueno Ferreira, Nadia Maria Batoreu, Paula Priscilla de Freitas, Martin Hernan Bonamino, Etel Rodrigues Pereira Gimba

-Affiliation of the Corresponding author (Etel Rodrigues Pereira Gimba):

Instituto Nacional de Câncer José Alencar Gomes da Silva, Rio de Janeiro, Brazil and Universidade Federal Fluminense, Rio de Janeiro, Brazil

-E-mail Address of the Corresponding author: etelgimba@id.uff.br 

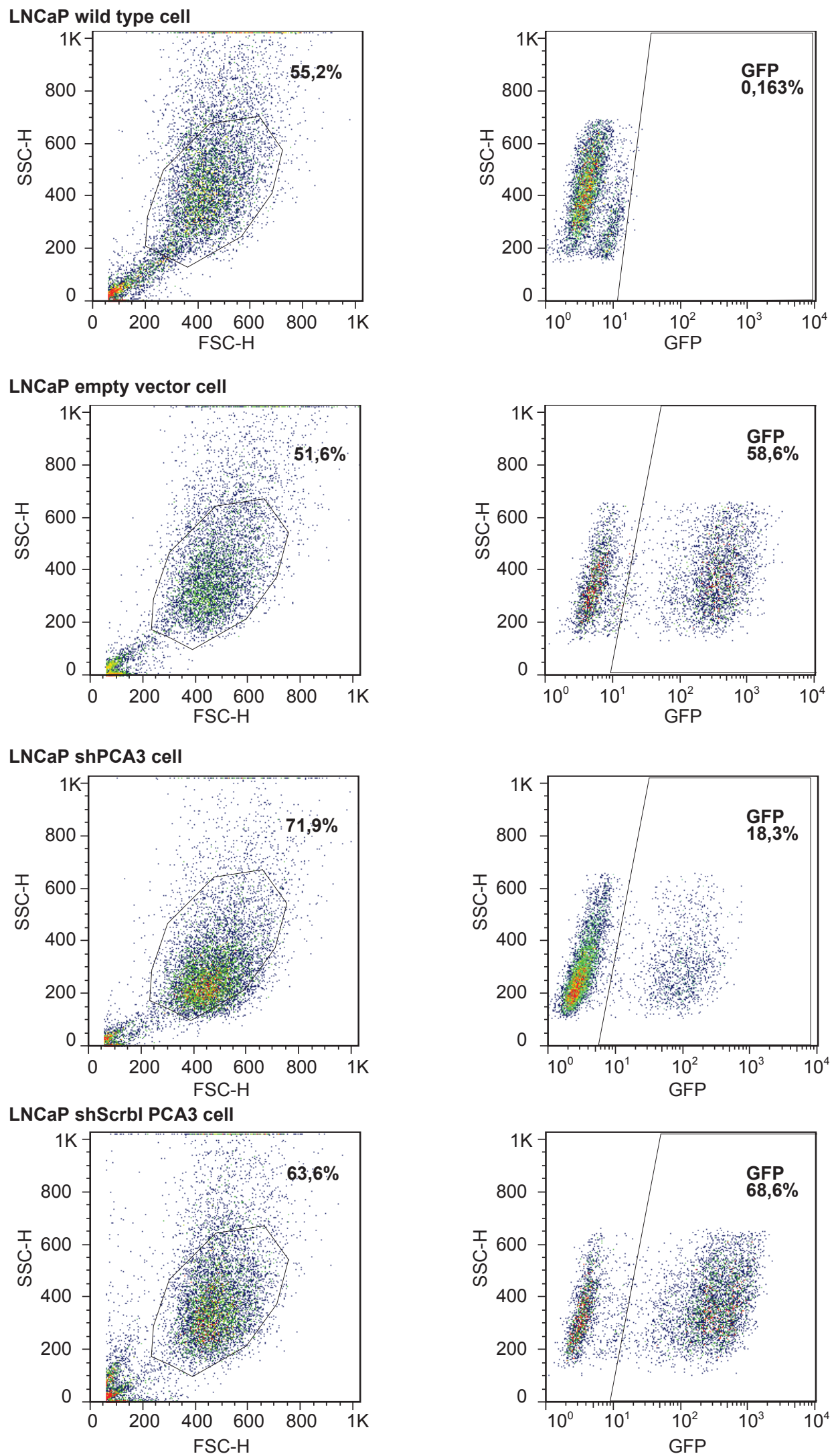

-Article Title: PCA3 long non-coding RNA modulates the expression of key cancer-related genes in LNCaP prostate cancer cells.

-Journal Name: Tumor Biology

-Authors names: Ana Emília Goulart Lemos, Luciana Bueno Ferreira, Nadia Maria Batoreu, Paula Priscilla de Freitas, Martin Hernan Bonamino, Etel Rodrigues Pereira Gimba

-Affiliation of the Corresponding author (Etel Rodrigues Pereira Gimba):

Instituto Nacional de Câncer José Alencar Gomes da Silva, Rio de Janeiro, Brazil and Universidade

Federal Fluminense, Rio de Janeiro, Brazil

-E-mail Address of the Corresponding author: etelgimba@id.uff.br 


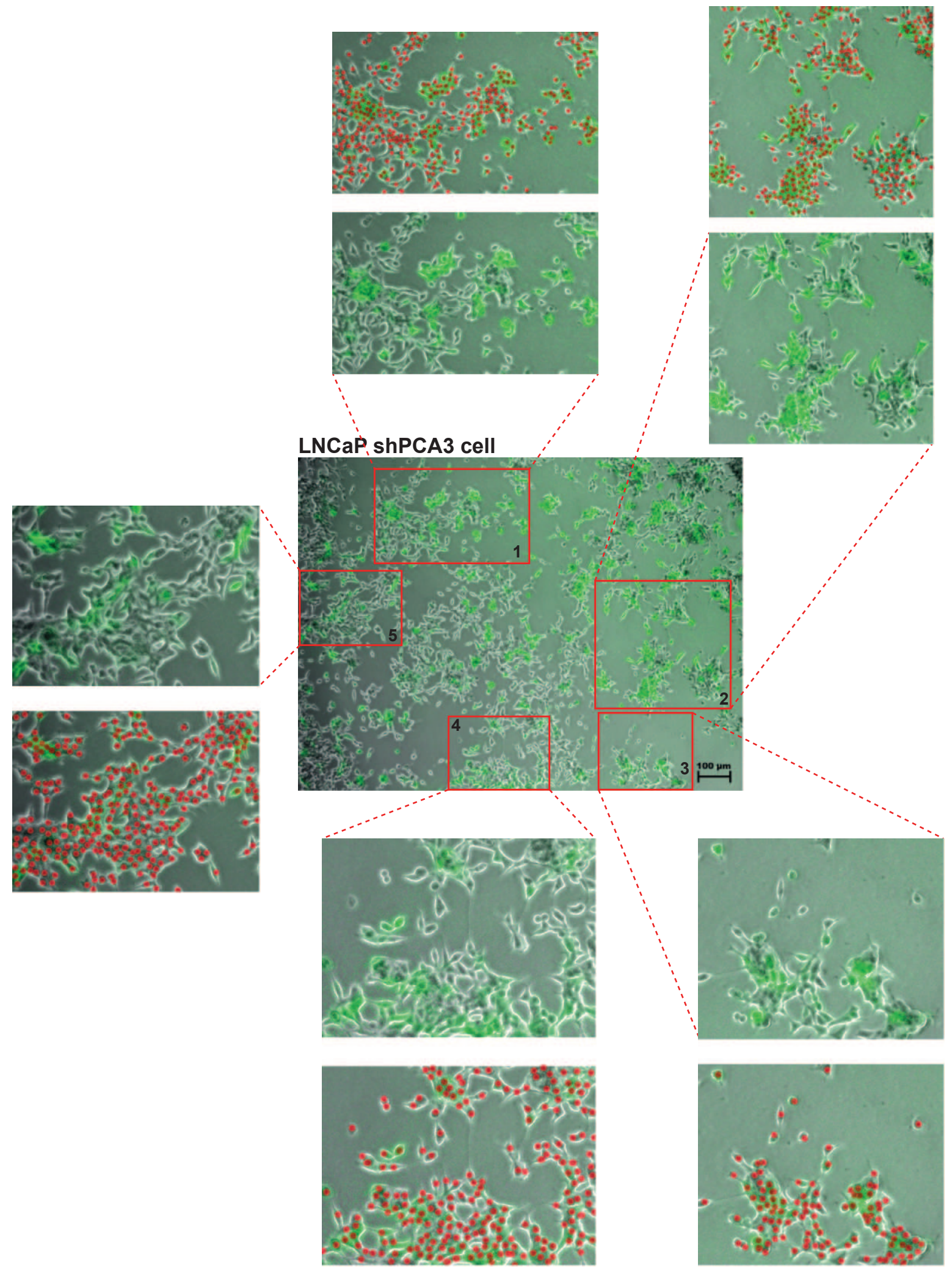

-Article Title: PCA3 long non-coding RNA modulates the expression of key cancer-related genes in LNCaP prostate cancer cells.

-Journal Name: Tumor Biology

-Authors names: Ana Emília Goulart Lemos, Luciana Bueno Ferreira, Nadia Maria Batoreu, Paula Priscilla de Freitas, Martin Hernan Bonamino, Etel Rodrigues Pereira Gimba

-Affiliation of the Corresponding author (Etel Rodrigues Pereira Gimba):

Instituto Nacional de Câncer José Alencar Gomes da Silva, Rio de Janeiro, Brazil and Universidade Federal Fluminense, Rio de Janeiro, Brazil

-E-mail Address of the Corresponding author: etelgimba@id.uff.br 